\title{
Knowledge, Perception, and Practice of DMPA-SC/Self-Injectable Contraceptive among Women: Findings from Mixed-Method Study in South-West and North-Central, Nigeria
}

\author{
Kehinde Osinowo ${ }^{1,2^{*}}$, Sambo-Donga Fintirimam ${ }^{1}$, Oluwaseun Ojomo ${ }^{1}$, Oladapo Ladipo ${ }^{1}$, \\ Peculiar Ojo $^{3}$, Tolulope Majiyagbe ${ }^{6}$, Esther Ishaya ${ }^{4}$, Landry Sagbo ${ }^{5}$ \\ ${ }^{1}$ Association for Reproductive and Family Health, Abuja Trade and Convention Center, \\ Behind Abuja Chamber of Commerce and Industry, Airport Road, Lugbe, Abuja-Nigeria \\ ${ }^{2}$ Department of Public Health, Texila American University, Guyana \\ ${ }^{3}$ Association for Reproductive and Family Health, RASuDiN project, Plateau State \\ ${ }^{4}$ Association for Reproductive and Family Health, RASuDiN project, Niger State \\ ${ }^{5}$ Association for Reproductive and Family Health, RASuDiN project, Lagos State \\ ${ }^{6}$ Association for Reproductive and Family Health, RASuDiN project, Oyo State
}

\begin{abstract}
Depot-Medroxyl-Progesterone-Acetate-Subcutaneous/Self Injection (DMPA-SC/SI) is an intentional approach used by the Nigerian government to improve the coverage rate of contraceptives method-mix. In this study, the knowledge, practice, and determinants of use of DMPA-SC/SI among women in NorthCentral and South-West, Nigeria, was assessed. A cross-sectional health facility study was conducted across four Nigerian states. Structured pretested questionnaires were used to elicit information from 844 women within reproductive age. Twenty focused group discussions and 40 In-depth interviews (IDIs). Descriptive statistics were used to analyze the characteristics of the women. Multivariate logistic regression was used to examine the determinants of the current use of DMPA-SC /SI. Statistical analyses were set at 5\%. Recorded voices were transcribed in full and analyzed using literary methods. About $89.5 \%$ of respondents reported ever heard family planning; $97.6 \%$ reported heard DMPA-SC; 83.2\% reported ever use family planning; $95.7 \%$ reported current use of family planning; $94.3 \%$ reported ever use DMPA-SC, and 46.5\% reported ever use DMPA-SC/SI. The reason for the use of DMPA-SC/SI was because it was easy to use, effective and self-administered. The factors that discourage women from using DMPA-SC/SI were mainly fears associated with side effects, for and fear of SI-self-injury. The logistic regression results showed that those residing in a rural part of the country were less likely to use DMPA-SC/SI. The government should scale up this model nationally, including rural and hard-to-reach communities with public awareness programmes, public sensitization, and refresher training to improve on Provider's counselling skills.
\end{abstract}

Keywords: Knowledge, Practice, Self-injectable contraceptive.

\section{Introduction}

Family planning and contraception can have a significant impact on avoiding unintended pregnancies, ensuring adequate birth spacing, improving maternal and child health indicators, and empowering women to improve their own and their families' health $[1,2]$.
Despite the established benefits of contraception, new information suggests that by the end of 2019, over 190 million women of reproductive age in the world had not used any form of contraception and that unintended pregnancy accounted for almost 45 percent of all conceptions $[1,3,4]$. 
Recently, there has been a noticeable increase in global funding and an emphasis on boosting contraceptive use [2]. The global contraceptive prevalence rate increased from 55 percent to 64 percent during the Millennium Development Goals (MDGs) period (1990-2015) [5]. However, not all parts of the world improved at the same rate.

For example, whereas the prevalence of contraception has increased dramatically in other parts of the world, Sub-Saharan Africa has lagged behind [1]. Contraception use has increased in Sub-Saharan Africa, although at a glacial pace. According to evidence, the contraceptive prevalence rate for SSA was barely 18.4 percent in 2015 [6]. Furthermore, contraception in SSA is higher among urbanbased households and those in resource-rich communities $[7,8]$.

Nigeria is one of the countries where all forms the contraceptive prevalence rate has minimally increased from 15.1 percent in 2013 to 16.6 percent in 2018, falling short of the government aim of 27 percent by 2020 [9]. However, as in other SSA nations, there is a difference in the use of modern contraception depending on where you live and the dichotomy between rural and Urban area. According to the National Demographic and Health Survey (2018), the prevalence of contraception in urban and rural Nigeria is 26.3 percent and 10.0 percent, respectively. In addition, the prevalence rate of injectable contraception was found to be 4.5 percent in the urban area and 2.5 percent in the rural area. Furthermore, the high contraceptive prevalence rate was recorded for South-West Nigeria $(35.1 \%)$ and lowest for North-West $(6.7 \%)$ [9].

When compared to South Asia (52\%) and East Asia (78\%) regions with high population density, Sub-Saharan Africa, particularly Nigeria, has high fertility rates and the lowest contraceptive prevalence rate in the world, with an average modern contraceptive prevalence rate (mCPR) of 30 percent and Nigeria at 12 percent [10]. Nigeria's population has been steadily increasing over the last decade, while the mCPR has remained stable [11]. The contraceptive prevalence rate (CPR) among currently married women aged 15 to 49 is 17 percent. The majority of currently married women who use contraception choose a modern method (12\%), whereas 5\% use a traditional method. The Federal Government of Nigeria, through the $\mathrm{FMoH}$, has set a target of 27 percent modern contraception prevalence by 2020 .

The government has established a national guidelines and training manuals for the introduction and scale-up of DMPA-SC selfinjection, among other things, to achieve this goal. Self-injection of DMPA-SC is an intentional strategy of the Nigerian government's national family planning goals to address the unmet need for contraception, and it has the potential to be a game-changer in terms of increasing and scaling up DMPA-SC. DMPASC/SI has been demonstrated to improve contraceptive prevalence rates in studies, although there is a gap in the predictors of method uptake and continuance across selfinjecting and provider-administered customers in Nigeria [12-14]. This study explored the knowledge, practice, and determinants of selfinjectable contraceptives among reproductiveage women in South West and North-Central Nigeria.

\section{Materials and Methods}

\section{Study Settings}

The study is conducted among women in South-West and North-Central Nigeria. Both political regions account for one-third of the population of women within the reproductive ages in Nigeria [15].

North-Central has six states (Niger, Kogi, Benue, Plateau, Nasarawa, and Kwara), including the Federal Capital Territory (FCT), and South-West has six states which are Ekiti state, Ondo states, Lagos state, Osun states, Ogun states, and the Oyo States. While the population of South West was put at 32.5 million 
people, that of North-Central is put at 45 million people.

\section{Study Design}

We conducted a descriptive cross-sectional health facility study among 844 women within reproductive age who registered for Family planning Clinics in four Nigerian States. The study population services is all the women within the reproductive age group who registered for Family planning Clinics in the selected health facilities at the time of the study.

\section{Sample Size Calculation}

Assuming a $50 \%$ health facility delivery in study area due to lack of reliable information, a z-score value of 1.96 for $95 \%$ confidence interval (CI), an error margin of 0.05 , a nonresponse rate of $10 \%$ a, a minimum sample size of 844 was worked out using the Cochrane's [16] formula for a single proportion.

\section{Sampling Procedure}

A multi-stage sampling procedure was used in selecting respondents for the study. In stage 1, we purposively selected two geopolitical zones, which are north-central and southwest. In stage 2 , a simple random sampling technique was used to select two states in each of the geopolitical zones.

In north-central, we selected Niger and Plateau States, while in the northwest, we selected Oyo and Lagos States. In stage 3, we obtained the lists of all the LGAs in each of the selected States, out of which $50 \%$ of the LGAs were selected, ensuring an equitable percentage of half-drawn from urban and a half from rural. In stage 4, simple random sampling was used to select 10 Primary Healthcare Centres in each of the LGA. In the final stage, respondents were selected from the health facility register. Reliability of the instrument was determined by pretesting of the instrument in another LGA among Women of reproductive age with similar demographic characteristics of the main Study site. After the Pretest the data was subjected to
Cronbach Alpha test to determine the reliability coefficient which gave a value of 0.5 .

\section{Inclusion/Exclusion Criteria}

The eligibility criteria include women within the reproductive ages that are 15-49 years, who were sexually active and mentally stable. We considered only women who were currently residing in the communities.

\section{Research Instrument}

Three research instruments were used for the study, and they are focused group discussion (FGDs); In-depth Interviews (IID), and a structured questionnaire. The questionnaire was self-structured and was administered in the English language. The questionnaire elicited information on women's socioeconomic characteristics; husband's socio-demographic data; women's reproductive characteristics; awareness, knowledge, and practice of family planning, experience with self-injected DMPA$\mathrm{SC}$, reasons for the use of self-injection, barriers to use of self-injection, negative influence to using DMPA-SC, what factors influence the use of DMPA-SC, what prompted women to take their last DMPA-SC, perception of quality of information given on DMPA-SC and description of the respondent experience of service delivery on DMPA-SC attitude of healthcare workers to respondent. The questionnaire was pretested by administering it to 20 women in a health centre that was not included in the study. The questionnaire was administered through face-toface interviews with respondents. However, where face-to-face contacts were not possible, mobile phones were used for data collection. The questionnaire was administered using an open data kit (ODK) in which the questionnaire called form was scripted into a computer and uploaded into a server. The completed forms were saved on the tablet and later uploaded into the server. The uploaded data were ready for error checking. A total of 20 FGDs were held among women of reproductive age in the four states. Each of the FGDs lasted between 45 minutes and 
an hour, and an end was put to each of the discussions when no further issue was raised. Each of the discussion featured between 10 and 12 participants who share similar socioeconomic characteristics. The number of participants were small enough to allow cordial conversation but large enough to allow divergent views [17].

The FGDs were held in Pidgin English and was recorded after permission was sought from participants.

Also, a total of 40 IDIs (10 per state) were conducted among family planning providers. IDIs lasted between 45 minutes and an hour. They were one-on-one interviews conducted with identified stakeholders and persons relevant to the focus of the research. Well-detailed FGDs and IDIs guides were used in conducting the interviews. The guides were structured to promote uniformity in the discussions. Some of the issues discussed in the FGDs and KIIs were the perception of women on DMPA-SC, the perception of the community on DMPA-SC, family planning practice, place of the utilization of DMPA-SC, motivation to use DMPA-SC, who decides about the number of children, factors that encourage the use of DMPA-SC; internal and external triggers to use DMPA-SC and factors that influence the ability to demand for DMPA-SC and availability of the products in the health facilities. Both FGDs and IDIs were audiotaped using NVIVO 12.0. In addition to the recording, a research assistant took notes using a template.

\section{Data Collection Procedure}

Trained field research assistants were used in collecting the data. Five research assistants, which comprised 3 community resource persons and 2 other persons with B.Sc. Degrees in health-related disciplines were recruited for data collection.

Research assistants were given training on the following areas: an overview of family planning, explanation of the study goals and objectives, study locations-urban and rural LGAs, study data collection, and ethics in the field survey.
Each of the research assistants was allocated 40 questionnaires, 3 IDIs, and 1 FGD.

\section{Dependent Variable}

The outcome indicator used in this study is the use of DMPA-SC. The outcome indicator is binary; hence women who reported current use of DMPA-SC were coded 1, while those who reported otherwise were coded 0 .

\section{Independent Variables}

For the dependent variable, we assessed the predictive value of several independent variables (covariate), which include maternal age, marital status, maternal education, occupation, place of residence, parity (number of children), number of children alive, desire for more children and geopolitical zones of residence were examined. Maternal age examined the respondents' current age, and we considered the following age groups: $<19 ; 20-29 ; 30-39$ and $\geq 40$ years. Marital status is considered the marital status of the respondents. We considered five marital categories which were married, single, separate, divorced, and widowed. Maternal education was considered the highest educational attainment of the respondents, and we considered the following groups: no formal education, primary, secondary and tertiary education. For occupation, we examined the following categories: housewife, artisan, farming, civil servant, trading, and student. Place of residence categorized the women into rural and urban. Parity examined the number of children the woman had ever given birth to, and the following categories were considered: none, 1-3, 4-6, and $\geq 7$. The number of children alive is considered the actual number of children alive out of the number of children to which the woman has given birth to. We considered the following categories: none, 1-3, 4-6, and $\geq 7$. A desire for more children considered whether the woman desire more children or not. Those who desire more children were coded 1 while otherwise coded 0 . The geopolitical zone categorized the women into South West and North Central. 
These variables were used by past studies that examined the determinants of family planning in Nigeria and elsewhere [18-22].

\section{Statistical Analysis}

Descriptive statistics was used to analyze the categorical and continuous variables of the socioeconomic characteristics of women of reproductive age. Cross-tabulation analysis was conducted to establish an association between dependent variables and selected independent variables. The Chi-square test was used to set variables that were statistically significant at $10 \%$. The binary logistic regression was used to examine determinants of the current use of DMPA-SC/SI among the women. Audio-taped voices were transcribed verbatim. Important themes related to the discussion were highlighted. Recorded voices were reported using translated quotations, which were denoted using brackets. The literal translation gave credibility to the reports. The In-depth Interview (IDI) and Focus Group Discussion were subjected to descriptive and inferential statistics using NVIVO version 12. Quantitative data collected was analyzed using Statistical Package for Service Solution (SPSS).

\section{Ethical Clearance and Approval}

Approval to conduct the study was gotten from the Nigerian Health Research Ethics Committee in line with the established guidelines of the Federal Ministry of Health. Approval was sought from the health facilities where the study was conducted. Informed consent was gotten from individual participants, having provided detailed information about the survey to them.

\section{Results}

Table 1. Socio-demographic Characteristics of the Respondents

\begin{tabular}{|l|l|l|}
\hline Variables & Frequency $(\mathbf{n}=\mathbf{8 4 4})$ & Percent \\
\hline Maternal age (years) & 2.1 \\
\hline$\leq 19$ & 18 & 40.4 \\
\hline $20-29$ & 341 & 41.3 \\
\hline $30-39$ & 348 & 16.2 \\
\hline$\geq 40$ & 137 & 85.1 \\
\hline Marital status & 9.5 \\
\hline Married & 718 & 2.6 \\
\hline Single & 80 & 1.3 \\
\hline Separate & 22 & 1.5 \\
\hline Divorced & 11 & \\
\hline Widowed & 13 & 9.6 \\
\hline Maternal education & 16.5 \\
\hline None & 81 & 47.4 \\
\hline Primary & 139 & 26.5 \\
\hline Secondary & 400 & \\
\hline Tertiary & 224 & 11 \\
\hline Occupation & 93 & 12.8 \\
\hline Housewife & 93 & 9 \\
\hline Artisan & 108 & 15.8 \\
\hline Farmer & 76 & 42.1 \\
\hline Civil Servant & 133 & \\
\hline Trading & 355 & \\
\hline
\end{tabular}




\begin{tabular}{|l|l|l|}
\hline Student & 79 & 9.4 \\
\hline \multicolumn{2}{|l|}{ Place of residence } & 45.6 \\
\hline Rural & 385 & 54.4 \\
\hline Urban & 459 & \\
\hline Parity (number of children) & 7.5 \\
\hline None & 63 & 49.5 \\
\hline $1-3$. & 418 & 37.2 \\
\hline $4-6$. & 314 & 5.8 \\
\hline$\geq 7$ & 49 & \\
\hline Number of children alive & 7.5 \\
\hline None & 63 & 53.9 \\
\hline $1-3$. & 455 & 35.7 \\
\hline $4-6$. & 301 & 3 \\
\hline$\geq 7$ & 25 & \\
\hline Desire for more children & 50.4 \\
\hline No & 425 & 49.6 \\
\hline Yes & 419 & 54 \\
\hline Geopolitical zone of residence \\
\hline Southwestern & 456 & 46 \\
\hline North central & 388 & \\
\hline
\end{tabular}

The respondents comprise of women between the ages of nineteen and forty-nine years. However, the majority of them, 689 (81.6\%), were women of age 20-39 years. Most of the respondents, $718(85.1 \%)$, were married women, about three quarter $73.9 \%$ of them had at least secondary level of education, 355 (42.2\%) were traders, while $385(45.6 \%)$ were rural dwellers. More so, 456 (54.0\%) were from the southwestern part of Nigeria, while 388 (46.0\%) were from the north-central part. About half 418 $(49.5 \%)$ of the women had 1-3 children, while about the same number of women still desire more children.

Table 2. Knowledge and Practice of DMPA-SC/SI among the Women

\begin{tabular}{|l|l|l|}
\hline Variables & Frequency $(\mathbf{n}=\mathbf{8 4 4})$ & Percent \\
\hline \multicolumn{2}{|l|}{ Ever heard of modern family planning method } \\
\hline No & 89 & 10.5 \\
\hline Yes & 755 & 89.5 \\
\hline Ever heard of DMPA-SC & 2.4 \\
\hline No & 20 & 97.6 \\
\hline Yes & 824 & 11.5 \\
\hline Ever heard of Self- Injection as a FP methods \\
\hline No & 97 & 88.5 \\
\hline Yes & 747 & 16.8 \\
\hline Ever used any modern family planning method \\
\hline No & 142 & 83.2 \\
\hline Yes & 702 & 4.3 \\
\hline Current use of family planning method (n= 702) \\
\hline No & 30 & \\
\hline
\end{tabular}




\begin{tabular}{|c|c|c|}
\hline Yes & 672 & 95.7 \\
\hline \multicolumn{3}{|c|}{ Ever used DMPA-SC $(n=702)$} \\
\hline No & 40 & 5.7 \\
\hline Yes & 662 & 94.3 \\
\hline \multicolumn{3}{|c|}{ Ever used Self-Injected DMPA-SC (n= 662) } \\
\hline No & 354 & 53.5 \\
\hline Yes & 308 & 46.5 \\
\hline \multicolumn{3}{|c|}{ The FP Method currently used $(n=672)$} \\
\hline DMPA-SC/SI & 620 & 92.3 \\
\hline Other modern FP & 52 & 9.7 \\
\hline
\end{tabular}

In Table 2, 89.5\% reported ever heard of the modern family planning method, and $97.6 \%$ reported ever heard DMPA-SC. About 83\% reported ever use of modern family planning methods. Also, $95.7 \%$ reported the current use of the family planning method. The result showed that $94.3 \%$ reported ever used DMPA-SC and $46.5 \%$ reported ever use of self-injectable DMPA-SC (see Figure 1). The majority of the respondents reported that they used selfinjectable DMPA-SC.

\section{Ever used DMPA-SC}

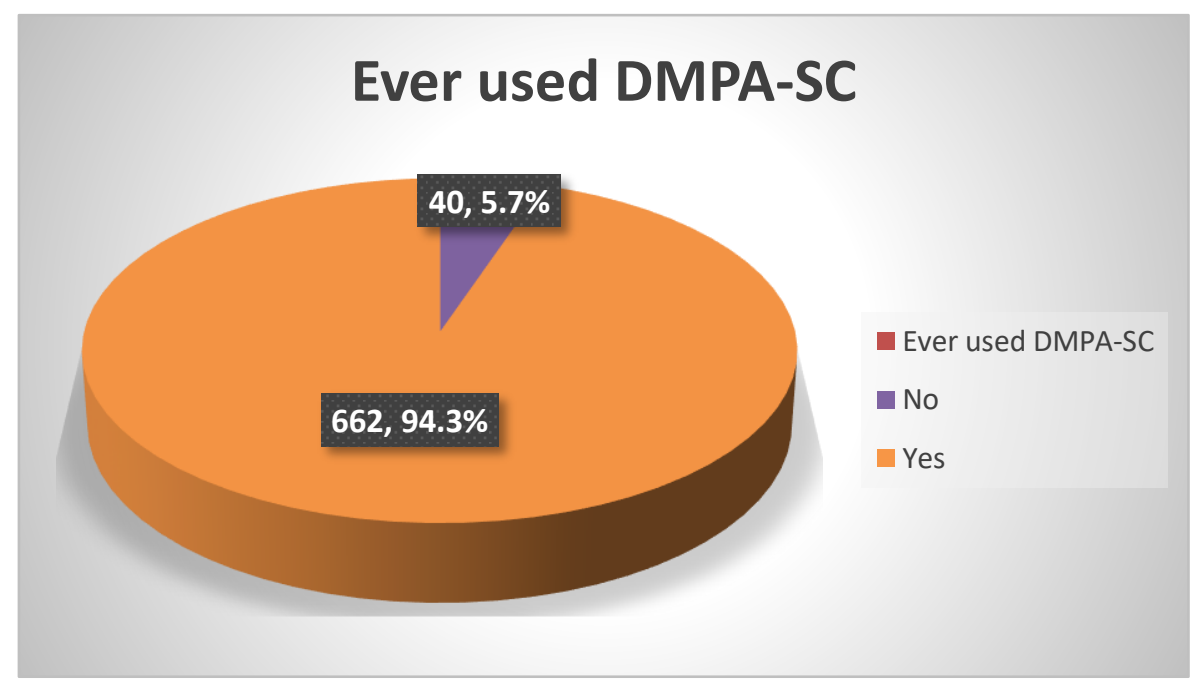

Figure 1. The Proportion of Mothers who Reported ever Use of DMPA-SC

\section{Ever self-injected DMPA-SC}

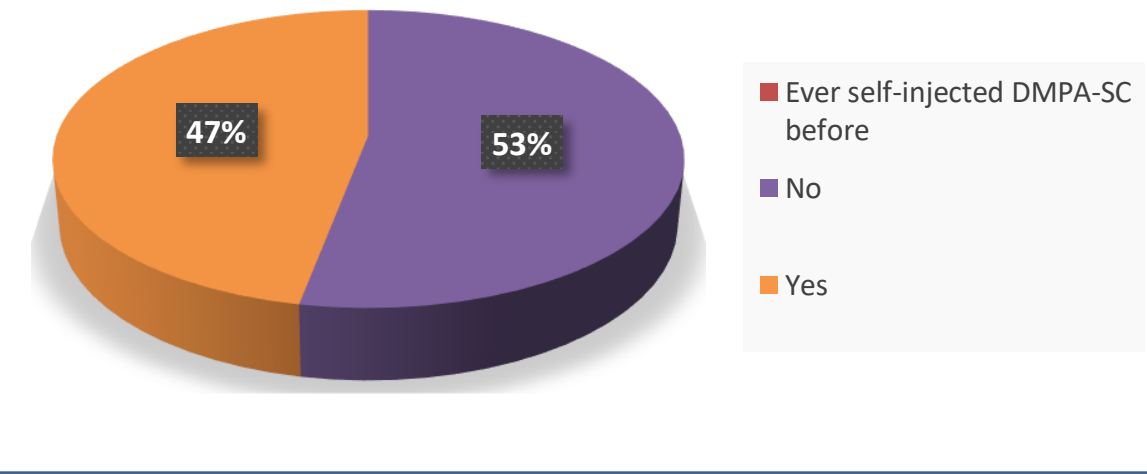

Figure. 2. The Proportion of Mothers who Reported ever Use of DMPA-SC/SI 
Table 3. Reasons for Use and Non-use of DMPA-SC/SI

\begin{tabular}{|l|l|l|}
\hline Variables & Frequency & Percent \\
\hline Negative influence to DMPA-SC/SI* & 424 & 51.5 \\
\hline Negative side effects of the method & 289 & 35.1 \\
\hline External influence from partner & 242 & 29.4 \\
\hline Religious reasons & 210 & 25.5 \\
\hline External influence from family members & \multicolumn{2}{l|}{} \\
\hline Positive influence to using DMPA-SC /SI & 298 & 45.0 \\
\hline Health benefits & 153 & 23.1 \\
\hline Financial implications & 118 & 17.9 \\
\hline Family and friends & 73 & 11.0 \\
\hline The effectiveness, safety and availability of the products & 20 & 3.0 \\
\hline Proximity of community Providers & \multicolumn{2}{l}{} \\
\hline Benefits associated with Self-injection & 278 & 42.0 \\
\hline It is easy to use and self-administered & 135 & 20.4 \\
\hline It is safe and dependable & 116 & 17.5 \\
\hline It helps in child spacing and prevention of unwanted pregnancy & 75 & 11.3 \\
\hline It is available, accessible and affordable & 58 & 8.8 \\
\hline It is provided free of charge & \multicolumn{2}{l}{} \\
\hline Fears associated with self-injection & 247 & 37.3 \\
\hline No fear at all & 101 & 15.3 \\
\hline Phobia for injection & 89 & 13.4 \\
\hline Fear of side effects & 88 & 13.3 \\
\hline Fear of self-injury & 79 & 11.9 \\
\hline Fear of wrong administration & 34 & 5.1 \\
\hline Fear of poor handling and storage & 15 & 2.3 \\
\hline Fear of husband approval & 9 & 1.4 \\
\hline Fear of availability & \multicolumn{2}{l}{} \\
\hline & 24 \\
\hline
\end{tabular}

*Multiple Responses

In Table 3, in order of hierarchy, the negative influence to use of injectable DMPA-SC are negative side effects of the method, husband discouragement, religious reasons, and discouragement from family members. On the other hand, positive influences to self-injectable DMPA-SC are health benefits and financial associated with self-injectable contraceptives are it is easy to use, and self-administered, it is safe and dependable and adequately helps in childbirth spacing. The fears associated with self-injectable contraceptives are phobia for selfinjection, fear of side effects, and fear of selfinjury from self-injection. implications. Furthermore, the benefits

Table 4a. Socio-demographic Characteristics of the Respondents and Current Use of DMPA-SC

\begin{tabular}{|l|l|l|l|}
\hline \multicolumn{5}{|c|}{ Current use DMPA-SC } \\
\hline Variables & Yes (n= 620) & No (n=52) & P-value \\
\hline Age (years) & $13(92.9)$ & $1(7.1)$ & 0.566 \\
\hline$\leq 19$ & $223(91.0)$ & $22(9.0)$ & \\
\hline $20-29$ &
\end{tabular}




\begin{tabular}{|l|l|l|l|}
\hline $30-39$ & $269(92.1)$ & $23(7.9)$ & \\
\hline$\geq 40$ & $115(95.0)$ & $6(5.0)$ & \\
\hline Marital status & \multicolumn{5}{|l|}{} \\
\hline Married & $544(92.7)$ & $43(7.3)$ & 0.500 \\
\hline Single & $41(87.2)$ & $6(12.8)$ & \\
\hline Separate & $16(94.1)$ & $1(50.9)$ & \\
\hline Divorced & $8(88.9)$ & $1(11.1)$ & \\
\hline Widowed & $11(91.7)$ & $1(8.3)$ & \\
\hline Highest educational level & & \\
\hline None & $52(89.7)$ & $6(10.3)$ & 0.381 \\
\hline Primary & $114(95.8)$ & $5(4.2)$ & \\
\hline Secondary & $276(91.7)$ & $25(8.3)$ & \\
\hline Tertiary & $178(91.8)$ & $16(8.2)$ & \\
\hline Occupation & $73(98.6)$ & $1(1.4)$ & $\mathbf{0 . 0 2 0}$ \\
\hline Housewife & $77(85.6)$ & $13(14.4)$ & \\
\hline Artisan & \multicolumn{5}{|l|}{} \\
\hline Farmer & $47(92.2)$ & $4(7.8)$ & \\
\hline Civil Servant & $116(95.9)$ & $5(4.1)$ & \\
\hline Trading & $268(91.5)$ & $25(8.5)$ & \\
\hline Student & $39(90.7)$ & $4(9.3)$ & \\
\hline Type of residence & & \multicolumn{1}{|l|}{} \\
\hline Rural & $202(85.6)$ & $34(14.4)$ & $<\mathbf{0 . 0 0 1}$ \\
\hline Urban & $418(96.9)$ & $18(4.1)$ & \\
\hline State of residence & $1439100.0)$ & $0(0.0)$ & $<\mathbf{0 . 0 0 1}$ \\
\hline Lagos & $129(79.6)$ & $33(20.4)$ & \\
\hline Oyo & $145(88.4)$ & $19(11.6)$ & \\
\hline Niger & $203(100.0)$ & $0(0.0)$ & \\
\hline Plateau & & \\
\hline
\end{tabular}

Table 4b. Socio-demographic Characteristics of the Respondents and Current Use of DMPA-SC

\begin{tabular}{|l|l|l|l|}
\hline \multicolumn{5}{|c|}{ Current use DMPA-SC } \\
\hline Variables & Yes (n= 620) & No (n=52) & P-value \\
\hline Geopolitical zone \\
\hline Southwest Nigeria & $272(89.2)$ & $33(10.8)$ & $\mathbf{0 . 0 0 9}$ \\
\hline Northcentral Nigeria & $348(94.8)$ & $19(5.2)$ & \\
\hline \multicolumn{5}{|l|}{} & \\
\hline Epe & $12(100.0)$ & $0(0.0)$ & $<\mathbf{0 . 0 0 1}$ \\
\hline Ifako Ijaiye & $131(100.0)$ & $0(0.0)$ & \\
\hline IBNE & $102(87.2)$ & $15(12.8)$ & \\
\hline Ido & $27(60.0)$ & $18(40.0)$ & \\
\hline Bassa & $83(100.0)$ & $0(0.0)$ & \\
\hline Jos South & $119(100.0)$ & $0(0.0)$ & \\
\hline Bosso & $84(95.5)$ & $4(4.5)$ & \\
\hline Tafa & $62(80.5)$ & $15(19.5)$ & \\
\hline Parity (number of children) & & \\
\hline
\end{tabular}




\begin{tabular}{|l|l|l|l|}
\hline None & $26(86.7)$ & $4(13.3)$ & 0.321 \\
\hline $1-3$ & $317(93.8)$ & $21(6.2)$ & \\
\hline $4-6$ & $240(90.9)$ & $24(9.1)$ & \\
\hline$\geq 7$ & $37(92.5)$ & $3(7.5)$ & \\
\hline Number of children alive & $26(86.7)$ & $4(13.3)$ & 0.103 \\
\hline None & $352(93.9)$ & $23(6.1)$ & \\
\hline $1-3$ & $224(90.0)$ & $25(10.0)$ & \\
\hline $4-6$ & $18(100.0)$ & $0(0.0)$ & \\
\hline$\geq 7$ & $301(91.5)$ & $28(8.5)$ & 0.474 \\
\hline Desire for more children & $319(93.0)$ & $24(7.0)$ & \\
\hline No & $1(33.3)$ & $2(66.7))$ & $\mathbf{0 . 0 1 7}$ \\
\hline Yes & $619(92.5)$ & $50(7.5)$ & \\
\hline Ever heard of DMPA-SC & & \\
\hline No & $35(81.4)$ & $8(18.6)$ & $\mathbf{0 . 0 1 3}$ \\
\hline Yes & $585(93.0)$ & $44(7.0))$ & \\
\hline Ever heard of self-injection &
\end{tabular}

Tables $4 \mathrm{a}$ and $4 \mathrm{~b}$ show the factors that are associated with respondents' current use of DMPA-SC. Respondents' occupation ( $\mathrm{p}=$ $0.020)$, type of residence ( $p<0.001)$, state of residence $(<0.001)$, geopolitical zone of residence $(\mathrm{p}=0.009)$, LGA of residence $(\mathrm{p}<$ $0.001)$, ever heard of DMPA-SC $(p=0.017)$, and ever heard of self-injection ( $p=0.013$ ) were found to be statistically significantly associated with current use of DMPA-SC.

Table 5. Logistic Regression Analysis to Determine the Predictors of Current Use of DMPA-SC among Respondents

\begin{tabular}{|l|l|l|l|}
\hline \multicolumn{5}{|c|}{ Current use of DMPA-SC } \\
\hline Predictors & Regression coefficient & AOR (95\% CI) & P-value \\
\hline Age (years) & 0.897 & $2.45(0.12-52.40)$ & 0.566 \\
\hline$\leq 19$ & 1.062 & $2.89(1.00-8.38)$ & $\mathbf{0 . 0 5 0}$ \\
\hline $20-29$ & 0.477 & $1.612(0.59-4.44)$ & 0.356 \\
\hline $30-39$ & \multicolumn{3}{|l|}{} \\
\hline$\geq 40$ & 1.311 & 1 & \\
\hline Highest educational level & $0.71(0.94-14.71)$ & 0.062 \\
\hline None & -0.607 & $0.57(0.16-1.81)$ & 0.322 \\
\hline Primary & -0.569 & 1 & 0.200 \\
\hline Secondary & \multicolumn{4}{|l}{} \\
\hline Tertiary & -0.673 & $0.51(0.04-6.26)$ & 0.599 \\
\hline Occupation & 1.966 & $7.14(1.47-34.69)$ & $\mathbf{0 . 0 1 5}$ \\
\hline Housewife & 0.749 & $2.1290 .30-14.77)$ & 0.450 \\
\hline Artisan & 0.964 & $2.62(0.49-14.13)$ & 0.262 \\
\hline Farmer & 1.363 & $3.91(0.88-17.25)$ & 0.072 \\
\hline Civil Servant &
\end{tabular}




\begin{tabular}{|c|c|c|c|}
\hline Student & & 1 & \\
\hline \multicolumn{4}{|l|}{ Type of residence } \\
\hline Rural & 2.407 & $11.10(5.12-24.10)$ & $<0.001$ \\
\hline Urban & & 1 & \\
\hline \multicolumn{4}{|l|}{ Geopolitical zone } \\
\hline Southwest Nigeria & 1.365 & $3.91(1.82-8.42)$ & $<0.001$ \\
\hline Northcentral Nigeria & & 1 & \\
\hline \multicolumn{4}{|c|}{ Ever heard of DMPA-SC } \\
\hline No & 3.521 & $33.80(2.22-515.64)$ & 0.011 \\
\hline Yes & & 1 & \\
\hline \multicolumn{4}{|c|}{ Ever heard of self-injection } \\
\hline No & 1.509 & $4.52(1.57-13.05)$ & 0.005 \\
\hline Yes & & 1 & \\
\hline
\end{tabular}

Respondents who were between the ages of $20-29$ years were found to be about 3 times statistically significantly more likely to be a current user of DMPA-SC when compare with those who were 40 years and above (AOR, 2.89; 95\% CI, 1.00-8.38; $\mathrm{P}=0.050$ ). Those who are artisans were 7 times statistically significantly more likely to be a current user of DMPA-SC when compare with those who are students (AOR, 7.14; 95\% CI, 1.47-34.69); $\mathrm{P}<0.015$ ). Respondents from the rural areas were 11 times statistically as likely to currently use DMPA-SC when compared with those from the urban areas (AOR, 11.10 95\% CI, 5.12-24.10; p <0.001). Respondents from the southwestern geopolitical zone $(3.91 ; 95 \%$ CI, 1.82-8.42; $\mathrm{p}<0.001)$, when compared with those from the north-central geopolitical zone, were found to be about 4 times more likely to currently using DMPA-SC. Those who have not heard about DMPA-SC (33.80; 95\% CI, 2.22-515.64; $p=0.011)$, compared to those who have heard about it, were statistically significantly more likely to currently use DMPA-SC/SI.

\section{In-depth Interview /Focused Group Discussion Sessions}

Two important themes were drawn from the FGDs and IIDs. The themes are: (i) Motivation to use IDIs (ii) Potential internal and external triggers that influence demand and uptake of modern FP methods, including DMPA selfinject.

\section{Motivation to Use DMPA-SC}

From the FGDs and IDIs, we gathered that there are some factors that serve as motivators to respondents who reported the use of selfinjectable contraceptive. Prominent among the factors were it is self-administered, costeffective, easy to use, and users do not need to frequently visit health facilities. In an in-depth interview, one of the participants has this to say:

"self-injectable contraceptive is effective, no complain of bleeding, and It reduces the number of the visit of clients to health facilities" [IDI Oyo State].

In another discussion, a participant remarked that the method was cheap, hence cost-effective.

"It saves cost; it is free and gives confidences to the women" [IDI- Oyo State].

We also noted that DMPA-SC appears to be more available that than contraceptive methods such as implants. This was reported by participants in the FGDs:

"When I was using the implant, access to the commodity was a problem because you have to go to and queue and wait you have to also pay, but this DMPA SC is easy because it does not take time and it does not waste time" [FGD-Plateau State]. 
Another motivating drive to use DMPA-SC/SI was that it has less issues of complication. Participants compared it with other methods and found it more attractive. It is less complicated. In one of the FGDs, a participant emphasized it:

"Self-injectable contraceptive is easy, and its complication are less, women complain about it less unlike the pills that you can forget, the loop you will bleed others are headache and what have you, in the ratio of women in the community of women using family planning method is the least women complain about its complications" [FGD-Plateau State].

Another participant has this to say:

"The absence of bleeding, overweight, DMPA$S C$ is good" [FGD-Tafa].

\section{Potential Internal and External Triggers that Influence Demand and Uptake of Modern FP Methods including DMPA Self-inject}

We also gathered from the FGDs and IDIs that there are both internal and external triggers that can influence the uptake of self-injectable DMPA-SC. Some of the triggers are costeffectiveness, the time it saves the respondents, partner/husband encouragement, and the anticipated benefits from its use. In one of the FGDs, a participant reported its costeffectiveness and that the method is cheap:

'The cost it is cost-effective; it is free, so there's no money attached to it. Then the proximity too is one of it, but probably because of the self-injection" [IDI- Lagos State].

Another participant remarked that the use of self-injectable DMPA-SC reduces the number of times the user visits health facilities:

"It's because of the method then the distance as well" [IDI- Lagos State].

'I think the only thing that makes them use it is that by the time they plan their family, they will be at rest, there will not be the issue of unwanted pregnancy, they will enjoy their husband, and they will enjoy their wife. I think that is one of the things that make them to turn out" [IDI-Oyo State].
Spousal encouragement was also reported in the FGDs:

"My husband encourages me." [IDI - Oyo].

\section{Discussion}

This study explored the knowledge, attitude, practice, and determinants of Depot Medroxyl Progesterone-Acetate-Subcutaneous/Self-

Injection (DMPA-SC/SI) among women in two geopolitical zones of Nigeria. The selected states were two (Lagos and the Oyo States) from the South Western geopolitical zone and two (Niger and Plateau States) from the North Central geopolitical zone. The result showed that $97.6 \%$ of the women reported they had heard of DMPASC, and $88.5 \%$ had heard of DMPA-SC/SI. However, this study is a follow-up to an aggressive campaign on family planning utilization among women and key decisionmakers in the northern part of the country. This may account for the high overall knowledge of DMPA-SC among the respondents. The focused group discussions showed that the majority of the respondents have heard of DMPA-SC and even self-injectable contraceptives.

The results demonstrated that contraceptive prevalence among the study participants was high (95.7\%), whereas current users of DMPASC were $92.3 \%$, while those who have ever selfinjected DMPA-SC $46.5 \%$. The usage rate of DMPA-SC recorded in this study is higher than national estimates $(21.8 \%)$ and the usage rate reported by past studies [23-26]. According to current scientific evidence, DMPA use has risen dramatically in Sub-Saharan Africa, and it is quickly becoming the most widely used modern method of contraception in many health facilities and reproductive and family health centers in Nigeria [27]. This could indicate that DMPA-SC is most commonly used for terminal contraception by women who have reached the end of their reproductive careers and want to stop having children [27]. This is not surprising given that the surgical method of contraception is not widely accepted by women in this society for cultural and religious [29, 30]. 
It was observed that reasons such as fear of self-injecting, fear of needle/ injection, and being unaware that one can actually self-inject herself were among the reasons more than half of the study participants never self-injected themselves. All these fears can be addressed or at least alleviated through appropriate training. The local government area in which the study areas are situated should organize periodic training where women are trained on how to inject themselves and handle the DSPA-SC in order to avoid self-injury. With the training, most of the women will become expertise, and that will avert all the fears that have been discouraging the use of injectable contraceptives. Men should also be trained so that they can assist women who cannot inject themselves.

When the usage of DMPA-SC was compared in terms or place of residence and geopolitical zones, it was observed that participants from urban areas and those from the North-Central region of the country respectively used the DMPA-SC method much more than their rural and southern dwelling counterparts. Availability of products, technically competent reproductive health practitioners, and health facilities may have helped in the higher rate of usage in the urban arrears compared to the rural areas, where there is the dearth of facility, professionals, and products due mainly because of security reasons, poor or non-existence of access road, and other infrastructures that can make life a bit easier and convenient for health care providers.

However, this study is a follow-up to an aggressive campaign on family planning utilization among women and key decisionmakers in the northern part of the country. Also, looking at the evidence from our findings that more than three-quarters of the participants from the northwestern zone started using DMPA-SC and other modern family planning methods less than three years ago (analysis withheld from the tables). We can deduce that these campaigns and other social mobilization and public enlightenments programs being carried out by non-profit organizations in the country and the effort of the government are yielding positive results among the targeted population. This could serve as a foundation for highlighting the study's findings. Lower fertility rates and longer birth spacing, which includes contraceptive use, can help to reduce maternal and child mortality rates. Other factors that can help are increased women's participation in the labor force, protection from abuse and violence, increased knowledge, improved decision-making power, and socioeconomic status. In addition, favorable trade policies and banking institutions should aid the expansion of profitable medium and smallscale firms. Women's economic empowerment could be improved by promoting it through local support groups, philanthropic organizations, well-off individuals, trade initiatives, and effective policies [31].

Though various factors were discovered to impact the use of DMPA-SC, both the household survey and the qualitative interviews show that cost-effectiveness, free charges for DMPA-SC, safety, effectiveness, self-administered, there are no cases of complications, and side effects (that is, bleeding, overweight and underweight), availability of services, lack of financial hardship and the fact that users do not need to visit health centres frequently were the motivating factors to use of DMPA-SC. Several other reasons were identified to promote or influence the use of modern contraceptive methods by the study participants. This study's findings suggest that efforts to promote healthy interpregnancy intervals are needed to reduce negative child health outcomes [23]. Furthermore, healthcare stakeholders would find the study's findings fascinating and useful as a foundation for policy design and implementation.

The result showed that appointment cards, telephone calls from healthcare providers, and the use of short messages were very helpful in motivating the women to initiate the use of DMPA-SC in particular and family planning in general. It is therefore important that these 
strategies be deployed in encouraging mothers to initiate contraception. Healthcare workers should have a list of women who are under their watch for contraceptives and send periodic messages to remind them of the initiation of contraception and progression.

Despite the utility from the results of this study, it has noteworthy limitations. First, the report analyzed was gotten through verbal reporting, and they were not validated using objective sources such as the use of health facility cards. Just like any other household survey, it is possible for respondents to give socially desirable responses. More so, because of the cross-sectional nature of the data, we could not explore the dynamic intertemporal relationship between the socio-demographic characteristics of the women and the use of family planning. Third, the number of observations used for the analysis is few; hence we cannot generalize the findings for the entire Nigerian population.

\section{Conclusion}

The results of the study showed a high contraceptive utilization rate $(95.7 \%)$ that far exceeds national estimates (22\%). Also, we noted that a high proportion of the women have heard of DMPA-SC and that slightly below average $(46.5 \%)$ reported ever use of DMPASC/SI. The utilization of self-injectable DMPASC recorded in this study is far above national estimates. This may be due to an earlier awareness campaign in the study area. The primary reasons why most respondents subscribed to the use of self-injectable DMPASC was because it is safe, easy to use, effective, and self-administered. Fears were associated with the use of self-injectable DMPA-SC, and common among the fears were phobias associated with self-injection, fear of side effects, and fear of self-injury. It will be helpful for an intervention programme to be conducted in the study area that will use health education, awareness, and public sensitization to educate mothers on the benefits of self-injectable contraceptives. Training programmes to help mothers learn how to inject themselves will allay the fear of self-injury associated with the method.

Furthermore, the result showed that respondents were drawn from South-West Nigeria, those residing in rural parts of the country and those who have not heard of selfinjectable DMPA-SC were less likely to report its use it. Intervention programme design to increase coverage use of this method of contraceptive must focus more on rural women and those from South-West Nigeria. Awareness programmes should be launched that educate mothers on the benefit of this method. The Government of Nigeria Should explore replicating this model across the $36+1$ states, as it has been perceived with evidence to be the Game Changer for increasing FP uptake.

\section{Acknowledgement}

The author appreciates the approval of the Association for Reproductive and Family Health for allowing this study to be conducted in four of the ten project states of Implementation. The contribution of all stakeholders and study participants in the four states is sincerely acknowledged.

\section{Ethics Approval and Consent to Participate}

Ethical clearance was obtained from the National Health Research Ethics Committee, Nigeria, for $\mathrm{PhD}$ primary research study in the four study sites.

\section{Consent for Publication}

No consent to publish was needed for this study as the author did not use any details, images, or videos related to individual participants.

\section{Conflict of Interest}

There was no conflicting interest in this study as it was a sole $\mathrm{PhD}$ primary Research by the author. 


\section{References}

[1] Moon TD, Okoth V, Starnes JR, et al. Determinants of modern contraceptive prevalence and unplanned pregnancies in Migori County, Kenya: results of a cross-sectional household survey. Afr $J$ Reprod Health 2021; 25: 29.

[2] Mochache V, Lakhani A, El-Busaidy H, et al. Pattern and determinants of contraceptive usage among women of reproductive age from the Digo community residing in Kwale, Kenya: results from a cross-sectional household survey. BMC Women's Health 2018; 18: 10.

[3] Ameyaw EK, Budu E, Sambah F, et al. Prevalence and determinants of unintended pregnancy in subSaharan Africa: A multi-country analysis of demographic and health surveys. PLoS ONE 2019; 14: e0220970.

[4] United Nations Department of Economic and Social Affairs. Family Planning and the 2030 Agenda for Sustainable Development (Data Booklet). United Nations. Epub ahead of print September 20, 2019. DOI: $10.18356 / \mathrm{e} 154 \mathrm{e} 49 \mathrm{~d}-\mathrm{en}$.

[5] Dasgupta ANZ, Wheldon M, Kantorova V, et al. Progress in Family Planning: Did the Millennium Development Goals Make a Difference? In: Population Association of America. Austin: Population Division, United Nations, Department of Economic and Social Affairs, 2019, p. 10.

[6] Ba DM, Ssentongo P, Agbese E, et al. Prevalence and predictors of contraceptive use among women of reproductive age in 17 sub-Saharan African countries: A large population-based study. Sex Reprod Health c 2019; 21: 26-32.

[7] Prata N, Weidert K, Fraser A, et al. Meeting Rural Demand: A Case for Combining Community-Based Distribution and Social Marketing of Injectable Contraceptives in Tigray, Ethiopia. PLoS ONE 2013; 8: e68794.

[8] Sileo KM, Wanyenze RK, Lule $\mathrm{H}$, et al. Determinants of family planning service uptake and use of contraceptives among postpartum women in rural Uganda. Int J Public Health 2015; 60: 987-997. [9] National Population Commission (NPC) [Nigeria] and ICF. 2019. Nigeria Demographic and Health Survey

2018 ,
https://www.dhsprogram.com/pubs/pdf/FR359/FR35 9 pdf (2019, accessed October 24, 2020).

[10] Total Fertility Rate in Nigeria Decreases Slightly as the Contraceptive Prevalence Rate Increases | JHU Advance Family Planning, https://www.advancefamilyplanning.org/totalfertility-rate-nigeria-decreases-slightlycontraceptive-prevalence-rate-increases (accessed July 10, 2021).

[11] National Population Commission. Nigeria Demographic and Health Survey 2018. Key Indicators Report, Nigeria: The DHS Program ICF Rockville, Maryland, USA.

[12] Cover J, Namagembe A, Tumusiime J, et al. Continuation of injectable contraception when selfinjected vs. administered by a facility-based health worker: a nonrandomized, prospective cohort study in Uganda. Contraception 2018; 98: 383-388.

[13] Kohn JE, Simons HR, Della Badia L, et al. Increased 1-year continuation of DMPA among women randomized to self-administration: results from a randomized controlled trial at Planned Parenthood. Contraception 2018; 97: 198-204.

[14]Liu J, Shen J, Diamond-Smith N. Predictors of DMPA-SC continuation among urban Nigerian women: the influence of counseling quality and side effects. Contraception 2018; 98: 430-437.

[15]Ahuru RR. The influence of women empowerment on maternal and childcare use in Nigeria. Int J Healthc Manag 2019; 1-10.

[16] Cochran WG. Professor of Statistics, Emeritus Harvard University. 10.

[17] Yaya S, Uthman OA, Ekholuenetale M, et al. Women empowerment as an enabling factor of contraceptive use in sub-Saharan Africa: a multilevel analysis of cross-sectional surveys of 32 countries. Reprod Health 2018; 15: 214.

[18] Aliyu AA, Dahiru T. Reproductive Health and Family Planning Services in Africa: Looking beyond Individual and Household Factors. In: Amarin Z, Abduljabbar $\mathrm{H}$ (eds) Family Planning and Reproductive Health. IntechOpen. Epub ahead of print December 2, 2020. DOI: 10.5772/intechopen.92138.

[19] Solanke BL. Factors influencing contraceptive use and non-use among women of advanced 
reproductive age in Nigeria. J Health Popul Nutr 2017; 36: 1 .

[20] Adebowale SA, Ajiboye BV, Arulogun O. Patterns and Correlates of Condom Use among Unmarried Male Youths in Nigeria: NDHS 2008. Afr J Reprod Health 2017; 17: 149-159.

[21] Kanwal N, Muttappallymyalil J, Al-Sharbatti S, et al. Contraceptive Utilisation Among Mothers of Reproductive Age in Ajman, United Arab Emirates. Sultan Qaboos Univ Med J 2017; 17: e50-e58.

[22] Olugbenga-Bello AI, Adebimpe WO, Akande $\mathrm{RO}$, et al. Health risk behaviors and sexual initiation among in-school adolescents in rural communities in southwestern Nigeria. Int J Adolesc Med Health 2014; 26: 503-510.

[23] Burke HM, Chen M, Buluzi M, et al. Effect of self-administration versus provider-administered injection of subcutaneous depot medroxyprogesterone acetate on continuation rates in Malawi: a randomised controlled trial. Lancet Glob Health 2018; 6: e568-e578.

[24] Ezegwui H, Ikeako L, Obiora-Okafor N. The use of Depot Medroxyprogesterone Acetate (DMPA) Injectable Contraceptive in Enugu, Nigeria. Niger J Med 2012; 21: 6 .

[25] Prabhakaran S, Sweet A. Self-administration of subcutaneous depot medroxyprogesterone acetate for contraception: feasibility and acceptability. Contraception 2012; 85: 453-457.

[26] Beasley A, White KO, Cremers S, et al. Randomized clinical trial of self-versus clinical administration of subcutaneous depot medroxyprogesterone acetate. Contraception 2014; 89: 352-356.

[27] Mairiga AG, Kyari O, Audu B, et al. Socioclinical characteristics of modern contraceptives users at the University of Maiduguri Teaching Hospital. Niger J Clin Pract 2007; 10: 152-155.

[28] Abasiattai A, Udoma E, Ukeme E. Depot medroxyprogesterone injectable contraception at the University of Uyo Teaching Hospital, Uyo. Ann Afr Med 2010; 9: 81.

[29]Ross J, Hardee K. Access to contraceptive methods and prevalence of use. J Biosoc Sci 2013; 45: 761-778.

[30] Ross J, Keesbury J, Hardee K. Trends in the Contraceptive Method Mix in Low- and MiddleIncome Countries: Analysis Using a New "Average Deviation" Measure. Glob Health Sci Pract 2015; 3: 34-55.

[31]Ross JA, Agwanda AT. Increased use of injectable contraception in sub-Saharan Africa. Afr J Reprod Health 2012; 16: 68-80. 